\title{
EVALUATION OF A KNOWLEDGE-BASED SYSTEM PROVIDING VENTILATORY MANAGEMENT AND DECISION FOR EXTUBATION
}

Michel Dojat (Ph.D.), Alain Harf (M.D.), Dominique Touchard, Martine Laforest, François Lemaire (M.D.), Laurent Brochard (M.D.)

Institut National de la Santé et de la Recherche Médicale INSERM U 296, Département de Physiologie, and Service de Réanimation Médicale, Hôpital Henri Mondor, Créteil, France.

Address for correspondence :

M.DOJAT

INSERM U296

Faculté de Médecine

8, rue du Général SARRAIL

94010 CRETEIL, FRANCE

Phone: 33148984603

Fax: 33148981777

e-mail: dojat@laforia.ibp.fr 


\section{ABSTRACT}

We evaluated whether a Knowledge-Based System (KBS) connected to a ventilator in pressure support mode could correctly predict the ability of patients to tolerate total withdrawal from ventilatory support. The KBS was designed to continuously adapt ventilatory assistance to the needs of the patient, to manage a strategy of gradually decreasing ventilatory assistance, and to indicate when the patient was able to breathe without assistance. Thirtyeight patients for whom weaning was being considered were evaluated using a conventional battery of parameters, including weaning criteria, tolerance of a Tpiece trial, and outcome 48 hours after permanent withdrawal of ventilation. The results of this evaluation were compared to the suggestions made by the KBS at the end of a period of KBS-driven mechanical ventilation inserted in the conventional weaning procedure. The positive predictive value of the KBS was $89 \%$, versus $77 \%$ for the conventional procedure and $81 \%$ for the rapid shallow breathing index alone. The KBS correctly predicted the course of five patients who tolerated a T-piece trial but required ventilation within 48 hours. We conclude that our KBS ensured appropriate patient management during the weaning period and improved our ability to predict responses to weaning.

Key Words: Weaning, Pressure Support Ventilation, Closed-loop Control. 
In intensive care units, prolonged mechanical ventilation initiated for acute respiratory failure is sometimes difficult to terminate (1). This situation, often referred to as "difficult weaning from mechanical ventilation", requires use of partial ventilatory support modalities, together with a medical strategy aimed at determining the best approach to weaning and at detecting the optimal moment for performing tracheal extubation. No clear guidelines for gradual weaning from mechanical ventilation have been published, in part because the reasons for prolonged mechanical ventilation and the underlying lung disease vary considerably across patients. Many investigators have emphasized the need for repeated careful clinical evaluation of ventilated patients (2-4). Patient management by specially-trained, experienced physicians who follow their own criteria is likely to improve the quality and success rate of weaning. Many ventilation-related decisions and ventilator setting changes are based on objective data, and the clinician's reasoning is essentially "data driven". Artificial intelligence techniques can be used to model such reasoning processes and to design a computerized system for ventilatory management. In the field of mechanical ventilation, several Knowledge-Based Systems (KBSs) have already been proposed. Most were diagnostic systems designed to make recommendations about ventilator settings (5-7). Very few incorporated a weaning strategy $(8,9)$. KBSs have the advantage of providing 24-hour a day management, potentially allowing continuous adaptation of the level of support and a reduction in the duration of mechanical ventilation. However, most systems proposed to date are open-loop control systems, and very few data on the clinical performance of KBSs have been reported.

Pressure Support Ventilation (PSV) is a mode of partial ventilatory support that is widely used during weaning from mechanical ventilation (1013). The physiological effects of PSV on breathing pattern and respiratory muscle function have been studied extensively (10-17). The relationship linking 
ventilator setting adjustment to work of breathing or patient effort on the one hand and to ventilatory pattern on the other seems to have been more extensively studied for PSV than for other modes of partial ventilatory support. Guidelines have been issued about use of PSV as full ventilatory support, and it has been suggested that the level of pressure needed by the patient may be useful for determining when extubation should be performed $(13,18,19)$. In addition, a protocol for gradual withdrawal from mechanical ventilation using PSV has proved to be extremely useful in difficult-to-wean patients (13).

We designed a closed-loop KBS for the management of assisted ventilation using PSV, including implementation of a weaning procedure. We report the results of a clinical evaluation of this system in 38 patients undergoing weaning from mechanical ventilation and of an assessment of the ability of the KBS to predict the right time for performing tracheal extubation.

\section{PATIENTS AND METHODS}

\section{$\underline{\text { Patients }}$}

Thirty-eight consecutive patients were selected for the study. Informed consent was obtained from each patient or next of kin. Patients were eligible when their physicians considered that weaning could be attempted. Because the objective of this study was to compare the decisional value of the KBS and of a conventional battery of tests, with each patient serving as his or her own control, and because only one system was working at a given time, we made no attempt to define weaning initiation. Rather, patients could be studied at different stages of the weaning procedure. However, all studied patients were receiving minimal or no sedation and were considered capable of breathing spontaneously with PSV on a continuous basis. Seven patients were ventilated mainly for an acute exacerbation of chronic obstructive lung disease, seven had 
postoperative complications of cardiac surgery, six had primarily central neurologic disorders, six had left heart failure, and 12 had miscellaneous disorders. Mean age was $56.7 \pm 14.5$ years. Main patients characteristics are shown in Tables 1 and 2. Mean values of the Simplified Acute Physiology Score (SAPS), which reflects overall disease severity at admission to the ICU (20), were $13.2 \pm 3.2$ in the 17 patients who were successfully weaned and $14.3 \pm 4.1$ in the 21 patients who remained dependent on mechanical ventilation.

\section{Description of the Knowledge-Based System}

The KBS used in this study has been described in detail elsewhere (21). Briefly, the closed-loop KBS acquires and processes data, evaluates the current respiratory status of the patient and its time-course, and acts directly on the ventilator. The KBS runs on a microcomputer placed at the patient's bedside and connected via two serial ports to a specially-adapted Veolar ventilator (Hamilton, Bonaduz AG, Switzerland). A gas analyzer that samples gas at the ventilator Y piece is also connected to another serial port. The KBS uses three main parameters, of which two are acquired from the ventilator, i.e., respiratory rate $(\mathrm{RR})$ and tidal volume $(\mathrm{Vt})$, and one from the gas analyzer, i.e., end tidal partial pressure of $\mathrm{CO}_{2}\left(\mathrm{P}_{\mathrm{ETCO}}\right)\left(\mathrm{CO}_{2}\right.$ monitor, 5200 Ohmeda, Maurepas, France).

The clinician's knowledge is modelled using forward chaining production rules. The knowledge base consists of 142 rules grouped into several rule bases corresponding to different cognitive steps. This partition facilitates representation of the clinician's knowledge in the manner needed to control the firing of the rules. A selection of the rules is shown in the appendix. The time-course of the patient's status is modelled as a state transition problem. Action plans are dynamically adapted depending on how long the patient has been in a given state. For example, pressure support level is decreased in the 
event of stable normal ventilation and increased in the event of persistent tachypnea.

The general strategy used was as follows: 1) the KBS tried to keep the respiratory rate between 12 and 28 breaths per minute, the tidal volume above a minimum threshold $(250 \mathrm{ml})$, and the $\mathrm{PETCO}_{2}$ below a maximum threshold (55 $\mathrm{mmHg}$, or $65 \mathrm{mmHg}$ for COPD patients); 2) all patients were ventilated in PSV mode, and to reach the above-defined targets the level of pressure support was periodically adjusted by the KBS; a positive end-expiratory pressure of 4 $\mathrm{cmH}_{2} \mathrm{O}$ was routinely added; 3 ) the KBS tried to reduce the level of pressure support level by steps of $2 \mathrm{cmH}_{2} \mathrm{O}$, taking into account the patient's breathing pattern history; and 4) when a threshold level of pressure support was reached (9 $\mathrm{cmH}_{2} \mathrm{O}$ for tracheally intubated patients, $5 \mathrm{cmH}_{2} \mathrm{O}$ for tracheotomized patients), an observation period (one or two hours according to whether the level of pressure support in the first hour of ventilation was $<15 \mathrm{cmH}_{2} \mathrm{O}$ or $\geq$ $15 \mathrm{cmH}_{2} \mathrm{O}$, respectively) was observed, and a decision about ventilator disconnection was then made by the KBS and displayed on the computer screen.

When the respiratory rate was above 28 breaths/min and both $\mathrm{P}_{\mathrm{ETCO}}$ and tidal volume were acceptable, the KBS increased assistance by $2 \mathrm{cmH}_{2} \mathrm{O}$; if respiratory rate exceeded 35 breaths/min, pressure support was increased by 4 $\mathrm{cmH}_{2} \mathrm{O}$. When respiratory rate was less than 12 breaths/min, the level of pressure support was decreased by $4 \mathrm{cmH}_{2} \mathrm{O}$. When tidal volume or $\mathrm{P}_{\mathrm{ETCO}}$ were outside defined ranges, the level of pressure support was increased by 2 $\mathrm{cmH}_{2} \mathrm{O}$. Depending on ventilation history, the KBS tolerated some instabilities and attempted a rapid decrease in the level of assistance.

All ventilator alarms remained available throughout the period of automatic control. The KBS did not require any external intervention, except before connection of the patient, when relevant information about the patient was entered (e.g., name, weight, intubation or tracheotomy, presence of 
COPD). In case of severe hypoventilation, the KBS switched the ventilatory mode to assist-control as a safety precaution. Special knowledge was introduced to allow differentiation between apnea and disconnection. Lastly, the KBS did not interfere with usual patient management: for instance, it was possible to perform endotracheal suctioning as often as required without any special maneuvers.

\section{$\underline{\text { Protocol }}$}

The protocol was approved by the Ethics Committee of the Henri Mondor Hospital. A period of assisted ventilation performed using the KBS was inserted in the conventional weaning procedure, which is aimed at deciding when to extubate. At the end of the process, decisions made using the two procedures were evaluated in a blind manner based on the final outcome of the patient. The following five steps were performed in a fixed order.

1) When discontinuation of mechanical ventilation was to be attempted, several weaning tests were performed by a physiotherapist. Frequency and volumes were measured using an electronic spirometer (SE 302T, Ohmeda, Maurepas, France). The tests were considered positive when three of the following four criteria were met: respiratory rate after disconnection 35 breaths/min or less, vital capacity above $10 \mathrm{ml} / \mathrm{kg}$, negative inspiratory pressure above $25 \mathrm{cmH}_{2} \mathrm{O}$, and arterial oxygen saturation greater than $90 \%$ for an inspired fraction of oxygen of 0.40 . When at least three criteria were met, a T-piece trial was done to evaluate breathing self-sufficiency. When less than three criteria were met, the patient was kept on assisted mechanical ventilation.

2) Before the T-piece trial (or the prolongation of assisted ventilation), the patient was connected to the KBS in the pressure support mode. The initial level of pressure was always $15 \mathrm{cmH}_{2} \mathrm{O}$. The KBS was run for a minimum of two hours to a maximum of 24 hours, depending in part on test results (KBS use was longer in patients with negative tests) and on the scheduled time of the 
T-piece trial. At the end of this period, a suggestion about extubation was made by the KBS but was not disclosed to the physician in charge. Throughout the period of assisted ventilation managed by the KBS, the level of pressure support was continuously adjusted by the KBS without any intervention of the staff.

3) Patients who had positive weaning tests underwent a T-piece trial to assess their ability to breathe spontaneously for two hours. After endotracheal suctioning, patients were disconnected from the ventilator and given humidified air and oxygen. Any of the following indicated failure of the T-piece trial: respiratory rate above 35 breaths/min and higher than the baseline rate; marked agitation or anxiety; diaphoresis; loss of consciousness; arterial oxygen desaturation (below 85\%) despite additional oxygen; respiratory acidosis $(\mathrm{pH}$ below 7.32) at the end of the two-hour period. Measurements were obtained every 30 minutes, or at more closely spaced intervals if needed. Respiratory rate was computed over one minute.

4) Patients who tolerated the two-hour T-piece trial underwent tracheal extubation, or permanent disconnection of the tracheotomy tube from the ventilator. Only those patients who were still extubated or disconnected after 48 hours were considered successfully weaned.

\section{$\underline{\text { Statistics }}$}

The number of patients identified by the KBS as likely to tolerate weaning was compared with the outcome of the conventional weaning procedure. Patients who failed the weaning tests or the T-piece trial or who required mechanical ventilation within 48 hours after extubation or disconnection were classified as true negatives (weaning failures) and all other patients as true positives (weaning successes). The following evaluations were made. The positive and negative predictive values (PPV and NPV) of the T- 
piece trial, the rapid shallow breathing index (1), and the KBS advice were compared. The following formulas were used to calculate NPV and PPV:

$\mathrm{NPV}=($ true negatives $/$ [true negatives + false negatives] $)$

PPV $=($ true positives $/$ [true positives + false positives] $)$

Data were expressed as means \pm standard deviations.

\section{RESULTS}

\section{Patients with negative weaning tests}

In 10 patients (see Table 1), the weaning tests were considered negative and no further attempt at separation from the ventilator was made on the same day. Each of these patients was connected to the KBS for a prolonged period (mean $14.2 \pm 5.1$ hours). In none did the KBS recommend tracheal extubation. At the end of the KBS-managed ventilation period, the pressure support level was $21.4 \pm 5.2 \mathrm{cmH}_{2} \mathrm{O}$.

\section{Patients with positive weaning tests}

Twenty-eight patients (see Table 2) with positive weaning tests were ventilated with the KBS for a mean of $10.4 \pm 7.8$ hours. A diagram of the protocol and of the outcomes is shown in Figure 1.

In 19 of these patients, the KBS decision recommended tracheal extubation or disconnection, based on the pressure support level and breathing pattern. All these patients were declared weanable based on good clinical tolerance of the minimal level of pressure support. Each of these 19 patients underwent a two-hour T-piece trial. Of the 17 who tolerated the trial and were extubated, all were still extubated and had a satisfactory clinical status after 48 hours. The RR/Vt ratio was less than 100 in 16 of these 17 patients. Figure 2 shows the pressure support level, respiratory rate, and tidal volume over time 
in a representative patient (patient 3) who was considered weanable by the KBS and successfully weaned. Two of the 19 patients (cases 18 and 21) failed to tolerate the T-piece trial and were kept on assisted mechanical ventilation with no attempt at weaning. Figure 3 illustrates the course of these two patients during KBS-managed ventilation. In both these patients, the level of pressure support was gradually decreased by the KBS.

In 9 patients, the KBS did not recommend tracheal extubation or complete disconnection from the ventilator after a mean of $11.2 \pm 8.1$ hours of KBS-managed ventilation. Since these patients had positive weaning tests, they underwent a T-piece trial as part of the conventional weaning procedure. Four (cases 25, 26, 27, and 28) rapidly failed the T-piece trial. The other five either had their tracheal tube removed (cases 19 and 20) or had their tracheotomy tube permanently disconnected from the ventilator (cases 22, 23 and 24). However, none of these five patients was still breathing spontaneously after 48 hours: two were reintubated (after 8 and 12 hours, respectively) and three were reconnected via their tracheotomy tube (after 2, 5 and 12 hours, respectively). Figures 4 and 5 depict the time-course of the KBS-adjusted pressure support level, respiratory rate, and tidal volume in these patients (cases 19 and 20 in Figure 4 and cases 22, 23, and 24 in Figure 5). All five patients needed a level of pressure support higher than the minimal value $\left(9\right.$ or $5 \mathrm{cmH}_{2} \mathrm{O}$ ) required by the KBS to recommend weaning. Responses of these patients in terms of pressure support, respiratory rate, and tidal volume during mechanical ventilation were very unstable as compared to those showed in Figure 2.

\section{$\underline{\text { Predictive values }}$}

The positive and negative predictive values of the different tests or procedures are shown in Table 3.

Tidal volume and rapid shallow breathing index values (not taken into account for the clinical decision) in the five patients who failed the T-piece trial 
(cases 19, 20, 22, 23, and 24) are reported in Table 2. In two of these patients (20 and 24), the rapid shallow breathing index was higher than 100 (respectively 142 and 133), which is predictive of weaning failure. In the other three patients (cases 19, 22, and 23), rapid shallow breathing index values were 80, 90, and 90, respectively, i.e., close to but lower than the threshold considered predictive of weaning failure.

Two patients (cases 18 and 21) were considered weanable by the KBS but failed the T-piece trial. The rapid shallow breathing index was 111 in patient 18; during the T-piece trial, he rapidly developed overt respiratory failure possibly due to pulmonary edema. This was interpreted as a possible side effect of PEEP removal during the T-piece trial. Patient 21 had a rapid shallow breathing index of 53 and failed the T-piece trial because of major desaturation and encephalopathy.

\section{DISCUSSION}

We found that KBS decisions about weaning made on the basis of pressure support level and breathing pattern compared favorably with decisions made after a conventional, more complex weaning procedure.

Artificial intelligence systems used in clinical settings have generally been developed to integrate the voluminous flow of information coming from the critical care environment and to manage this information in real-time. For a number of reasons including the complexity of medical reasoning, interference from noise, liability considerations, and social and cultural factors, most intelligent monitoring systems are open-loop systems with respect to planning and control (22). Our KBS, which performs monitoring and interpretation tasks, also executes the treatment plans it proposes. It works as a closed-loop, since it controls the level of pressure support. This is possible because of the relatively 
limited period of time covered by the KBS (the period of weaning from mechanical ventilation), the single ventilatory mode used, and the capability to formalize and to represent, on a computer, part of the knowledge acquired over these past ten years about both breathing patterns during acute ventilatory failure and pressure support ventilation $(12,23)$. A previous study showed that our KBS was able to maintain the breathing pattern within a zone of respiratory comfort (21). Patients who had positive weaning tests were kept out of critical zones (respiratory rate $<12$ breaths/min, or respiratory rate $>35$ breaths/min or tidal volume $<250 \mathrm{ml}$ ) for $99 \%$ of the duration of total ventilation, and patients who failed weaning tests for $90 \%$ of this duration. During acute respiratory failure and in the absence of severe hypoxemia, the breathing pattern is an integrated marker of the information coming to the central nervous system from the different loads or stimuli imposed on the respiratory system (23). Most of this information is related to the load placed on the respiratory muscles, which carries a variable risk of muscle fatigue. Pressure support is an imperfect but useful model of breath-by-breath respiratory muscle unloading (12). During PSV, the information gained from breathing pattern analysis remains reliable and can be used as a guide for setting the pressure level (13). Control of the mechanical ventilator also implies that alarms are taken into account and appropriate responses provided in life-threatening situations such as apnea or severe hypoventilation. For instance, the presence of a $4 \mathrm{cmH}_{2} \mathrm{O}$ PEEP, primarily aimed at facilitating triggering of the ventilator (24) and improving oxygenation, indicates, in the absence of tidal volume, apnea rather than disconnection (PEEP cannot be maintained during disconnection), two situations that lead to different responses. In addition, end-tidal pressure of $\mathrm{CO}_{2}$ is used as a safety parameter and can help to decide whether a switch to controlled ventilation is appropriate in a patient with severe hypoventilation. A computer-controlled ventilator weaning system using a similar approach has been used in post-operative patients (25). The rate of mechanical breaths was 
decreased first and the level of pressure support subsequently. Respiratory rate, minute ventilation, and pulse oximeter oxygen saturation were used as guides for weaning. Similarly, our KBS is integrated into the routine data-management environment. This is a key feature to its routine use and acceptability to users (26).

Medical decision-support systems have rarely been evaluated in clinical settings (27). Although such evaluations are considered mandatory, no clear guidelines for conducting and interpreting them have been published to date (28). It is possible to evaluate several aspects of the system, reflecting benefits for the patient, user or health care institution.

Our evaluation of our KBS focused on the reliability of the decision about withdrawal of ventilatory assistance. This decision (or recommendation) is based on a period of observation during which the patient receives the lowest level of pressure allowed $\left(9 \mathrm{cmH}_{2} \mathrm{O}\right.$ in patients with a nasally or orally inserted tracheal tube, $5 \mathrm{cmH}_{2} \mathrm{O}$ in patients with a tracheotomy tube). The assumption underlying this approach is that these levels of pressure help to counteract the extra load imposed by the demand valve and the endotracheal tube $(18,19)$. We found in a previous study that the level, which effectively couteracts the extra load, varied across individuals and that part of the changes in work of breathing observed after extubation resulted from a change in ventilatory requirements (19). In vitro experiments have also demonstrated that this level varies with the endotracheal tube inner diameter (18). Therefore, use of a fixed level in all patients may be overly restrictive or inaccurate. On the other hand, relatively large fluctuations in breathing pattern were allowed during this period of observation, making the test less restrictive. Results with our KBS were as good as, and even slightly better than, those with the conventional, more complex weaning procedure or with the rapid shallow breathing index proposed by Yang and Tobin (1). However, the number of patients was small. Furthermore, there were variations across patients in pre-test duration of 
mechanical ventilation, which is an important factor tending to reduce the reliability of most weaning tests. Interestingly, our KBS predicted failure of weaning (or more precisely did not suggest extubation) for five patients who tolerated the two-hour T-piece trial but eventually failed to tolerate weaning. Continuous observation of the patient as provided by the KBS may be more efficient than intermittent observations for some patients. Also, continuous monitoring of end-tidal $\mathrm{CO}_{2}$ pressure and tidal volume by the KBS may be an advantage compared to conventional procedure. However, rapid shallow breathing index in these patients were either high (142 and 133 for patients 20 and 24, respectively) or borderline $(80,90$, and 90 for patients 19,22 , and 23, respectively). Although studies in much larger samples of patients are needed to confirm these results, our KBS may be particularly helpful for making decisions in borderline patients.

Patients 18 and 21, for whom the KBS recommended extubation, failed to tolerate the T-piece trial. For these two patients, underestimation of the respiratory rate due to inspiratory efforts failing to trigger the ventilator may have caused the KBS to make an wrong decision. Ineffectual efforts, however, occur chiefly at high levels of pressure support when the respiratory drive of the patient is insufficient to trigger the ventilator. It is therefore unlikely that ineffectual efforts constitute a major problem at the low levels of pressure support used by our KBS to test the ability of the patient to sustain spontaneous ventilation. In addition, routine use of a low level of external PEEP helps to counteract potential difficulties in triggering the ventilator due to intrinsic PEEP. The false positive result in patient 18 was perhaps due to the use of PEEP during ventilatory support. Removal of PEEP (during the T-piece trial and after extubation) led to left heart failure and respiratory distress. Patient 21 failed to tolerate weaning because of oxygenation and neurological problems. These two aspects of the overall status of the patient may influence weaning and are 
clearly not taken into account by our KBS, although oxygenation problems usually influence respiratory rate, even during pressure support (29).

To assess the value of the KBS recommendation, we compared a few hours of ventilation with the KBS to a weaning procedure including several weaning tests and tolerance of a two-hour T-piece trial. Use of a two-hour Tpiece trial as pre-extubation test has been studied previously $(13,30)$. The reintubation rate after this test has varied from $0 \%$ to $20 \%$, a range that is consistent with our findings. Whether patients who fail to tolerate the T-piece trial would develop respiratory failure should they be extubated remains unknown. Weaning tests are known to have low predictive values (1). Our main reason for using them is that their negative predictive value can be considered acceptable. A threshold of $20 \mathrm{cmH}_{2} \mathrm{O}$ for the maximal negative inspiratory pressure, for instance, had a negative predictive value of $100 \%$ in a prospective study by Yang and Tobin (1). To evaluate the capability of an automatic computerized system to correctly predict the success or failure of extubation of patients ventilated in pressure support mode, we needed to compare the new method to conventional procedure. Our protocol probably prolonged ventilatory support in 17 patients who were successfully separated from the ventilator. This was, however, due only to the design of the study, which involved insertion of a period of KBS-driven ventilation within the conventional procedure. Our KBS is designed both to administer ventilatory support and to judge the ability of the patient to be weaned. Therefore, in theory, the minimal pressure requirement should be met earlier than in this study. This could be tested in the future, by looking at the total duration of ventilation.

Weaning is easily and rapidly achieved in many patients receiving mechanical ventilation. In others, especially after prolonged mechanical ventilation and in the presence of an underlying lung disease such as chronic airflow obstruction, weaning can be a long and difficult process. During this 
period, careful adaptation of the ventilatory support to the needs of the patient seems important to avoid excessive work of breathing and effort, discomfort, and dyspnea. Inadequate support is associated with increased oxygen consumption and catecholamine release and may precipitate cardiovascular dysfunction (31-33). Adjustment of pressure support based on breathing pattern and clinical status may have favorable effects on the outcome of weaning as compared with other strategies using more aggressive unloading (13). A crucial problem is to determine the optimal time for performing tracheal extubation. Both undue prolongation of mechanical support and reintubation carry a risk of nosocomial pneumonia with prolonged an increased duration of the stay in the intensive care unit and excess mortality (34). The level of pressure support may be a useful guide for determining when extubation should be performed but should be viewed as an aid to the physician, who should also consider other criteria. As discussed above, use of the level of pressure support has several limitations. In particular, a need for a high level of pressure support can be due to partial endotracheal tube obstruction rather than to abnormal respiratory mechanics; failure to recognize this can lead to overestimation of the needs of the patient and to an inappropriate decision not to attempt weaning.

In conclusion, we found that KBS-managed ventilation in the pressure support mode until extubation or disconnection can be used in mechanically ventilated patients near the weaning period. The potential advantages of this approach, which have not been proven in our study, may be improved adaptation of ventilatory assistance to the needs of the patient, a reduced need for monitoring, and better weaning outcomes. 


\section{$\underline{\text { Acknowledgements }}$}

We thank Josef X. Brünner and Hamilton Medical AG for their help in designing this study. 


\section{REFERENCES}

1. Yang, K. L., M. J. Tobin. 1991. A prospective study of indexes predicting the outcome of trials of weaning from mechanical ventilation. N. Engl. J. Med. 324:1445-1450.

2. Marini, J. J. 1991. Weaning from mechanical ventilation. N. Engl. J. Med. 324:1496-1498.

3. Tobin, M. J., K. Yang. 1990. Weaning from mechanical ventilation. In M. J. Tobin, editor. Critical Care Clinics. Mechanical Ventilation, Saunders, Philadelphia. vol. 6:725-748.

4. Lemaire, F. 1994. Le sevrage de la ventilation mécanique. In L. Brochard and J. Mancebo, editors. Ventilation Artificielle. Principes et applications, Arnette, Paris. 275-286.

5. Sittig, D. F., N. L. Pace, R. M. Gardner, E. Beck and A. H. Morris. 1989. Implementation of a computerized patient advice system using the HELP clinical information system. Comput. Biomed. Res. 22:474-487.

6. Rutledge, G. W., G. E. Thomsen, B. R. Farr, M. A. Tovar, J. X. Polaschek, I. A. Beinlich, L. B. Sheiner and L. M. Fagan. 1993. The design and implementation of a ventilator management advisor. Artif. Intell. Med. 5:67-82.

7. Hayes-Roth, B., R. Washington, D. Ash , R. Hewett, A. Collinot, A. Vina et al. 1992. Guardian: a prototype intelligent agent for intensive-care monitoring. Artif. Intell. Med. 4:165-185 
8. Tong, D. A. 1991. Weaning patients from mechanical ventilation. A knowledge-based system approach. Comput. Meth. Prog. Biomed. 35:267-278.

9. Rudowski, R., C. Frostell and H. Gill. 1989. A knowledge-based system for mechanical ventilation of the lungs. The KUSIVAR concept and prototype. Comput. Biomed. Res. 30:59-70.

10. MacIntyre, N. R. 1989. Respiratory function during pressure support ventilation. Chest 89:677-683.

11. Brochard, L., F. Pluskwa, F. Lemaire. 1987. Improved efficacy of spontaneous breathing with inspiratory pressure support. Am. Rev. Respir. Dis. 136:411-415.

12. Brochard, L., A. Harf, H. Lorino, F. Lemaire. 1989. Inspiratory pressure support prevents diaphragmatic fatigue during weaning from mechanical ventilation. Am. Rev. Respir. Dis. 139:513-521.

13. Brochard, L., A. Rauss, S. Benito, G. Conti, J. Mancebo, N. Rekik, A. Gasparetto, F. Lemaire. 1994. Comparison of three methods of gradual withdrawal from ventilatory support during weaning from mechanical ventilation. Am. J. Respir. Crit. Care Med. 150:896-903.

14. Van de Graaff, W. B., K. Gordey, S. E. Dornseif, D. J. Dries, B. S. Kleinman, P. Kumar, M. Mathru. 1991. Pressure support. Changes in ventilatory pattern and components of the work of breathing. Chest 100:1082-1089.

15. Ershowsky, P., B. Krieger. 1987. Changes in breathing pattern during pressure support ventilation. Resp. Care. 32:1011-1016. 
16. Tokioka, H., S. Saito, F. Kosaka. 1989. Effect of pressure support ventilation on breathing pattern and respiratory work. Intens. Care Med. 15:491-494.

17. Annat, G. J., J. P. Viale, C. P. Derymez, Y. M. Bouffard, B. X. Delafosse, J. P. Motin. 1990. Oxygen cost of breathing and diaphragmatic pressure time-index. Measurement in patients with COPD during weaning with pressure support ventilation. Chest 98:411-414.

18. Fiastro, J. F., M. P. Habib, S. F. Quan. 1988. Pressure support compensation for inspiratory work due to endotracheal tubes and demand continuous positive airway pressure. Chest 93:499-505.

19. Brochard, L., F. Rua, H. Lorino, F. Lemaire, A. Harf. 1991. Inspiratory pressure support compensates for the additional work of breathing caused by the endotracheal tube. Anesthesiology 75:739-745.

20. Le Gall, J. R., P. Loirat, A. Alperovitch, P. Glaser, C. Granthil, D. Mathieu, P. Mercier, R. Thomas, D. Villers. 1984. A simplified acute physiologic score for ICU patients. Crit. Care Med. 12:975-977.

21. Dojat, M., L. Brochard, F. Lemaire, A. Harf. 1992. A knowledge-based system for assisted ventilation of patients in intensive care. Int. J. Clin. Monit. Comput. 9:239-250.

22. Uckun, S. 1993. Intelligent systems in patient monitoring and therapy management: a survey of research projects. Technical report. Stanford University, CA. No. KSL 93-32. 
23. Tobin, M. J., W. Perez, S. H. Guenther, B. J. Semmens, M. J. Mador, S. J. Allen, R. F. Lodato, D. Dantzker. 1986. The pattern of breathing during successful and unsuccessful trials of weaning from mechanical ventilation. Am. Rev. Respir. Dis. 134:111-118.

24. Smith, Th., J. J. Marini. 1988. Impact of PEEP on lung mechanics and work of breathing in severe airflow obstruction. J. Appl. Physiol. 65:1488-1499.

25. Strickland, J. H. and Hasson J. H. 1991. A computer-controlled ventilator weaning system. Chest 100:1096-1099.

26. Shortliffe, E. H. 1993. The adolescence of AI in Medicine: will the field come of age in the '90s? Artif. Intell. Med. 5:93-106.

27. Wyatt, J. and Spiegelhalter D. 1990. Evaluating medical expert systems: what to test and how? Med. Inf. 15:205-217.

28. Grogono, P., A. Batarekh, A. Preece, R. Shinghal R and C. Suen. 1991. Expert system evaluation techniques: a selected bibliography. Expert Systems 8:227-239.

29. Pesenti, A., N. Rossi , A. Calori, G. Foti , G. P. Rossi. 1993. Effects of shortterm oxygenation changes on acute lung injury patients undergoing pressure support ventilation. Chest 103:1185-1189.

30. Gandia, F., J. J. Blanco. 1992. Evaluation of indexes predicting the outcome of ventilator weaning and value of adding supplemental inspiratory load. Intens. Care Med. 18:327-333. 
31. Field, S., S. M. Kelly, P. T. Macklem. 1982. The oxygen cost of breathing in patients with cardiorespiratory disease. Am. Rev. Respir. Dis. 126:9-13.

32. Oh, T. E., S. Bhatt, S. Lin, R. C. Hutchinson, J. M. Low. 1991. Plasma catecholamines and oxygen consumption during weaning from mechanical ventilation. Intens. Care Med. 17:199-203.

33. Lemaire, F., J. L. Teboul, L. Cinotti, G. Giotto G, F. Abrouk, G. Steg, I. Macquin-Mavier, W. M. Zapol. 1988. Acute left ventricular dysfunction during unsuccessful weaning from mechanical ventilation. Anesthesiology 69:171-179.

34. Fagon, J. Y., J. Chastre , A. J. Hance, P. Montravers, A. Novara, C. Gibert. 1993. Nosocomial pneumonia in ventilated patients: A cohort study evaluating attributable mortality and hospital stay. Am. J. Med. 94:281-288. 


\section{Figure legends}

Figure 1: Diagram showing the design and results of the clinical study.

Figure 2: Time-course of respiratory rate (RR), tidal volume (Vt), and level of pressure support set by the knowledge-based system in case 3, who was declared weanable by the knowledge-based system and successfully weaned. The level of pressure support was continuously decreased, and the physiological parameters RR and Vt remained within acceptable ranges.

Figure 3: Time-course of respiratory rate (RR), tidal volume (Vt), and level of pressure support set by the knowledge-based system in cases 18 and 21, who were considered weanable by the knowledge-based system because of the low level of assistance reached $\left(9 \mathrm{cmH}_{2} 0\right)$. Neither patient tolerated the two-hour Tpiece trial. See text for details.

Figure 4: Comparison of the time-course of respiratory rate (RR), tidal volume $(\mathrm{Vt})$, and level of pressure support set by the knowledge-based system in patients 19 and 20, who were placed by the knowledge-based system at a high level of pressure support $\left(29 \mathrm{cmH}_{2} \mathrm{O}\right.$ in patient 19 and $26 \mathrm{cmH}_{2} \mathrm{O}$ in patient 20) because of a fast unstable respiratory rate (above 28 breaths/min in case 19) or a low tidal volume (case 20). The knowledge-based system did not recommend withdrawal of mechanical assistance in either patient. Both tolerated the twohour T-piece trial but required reventilation within 48 hours.

Figure 5: Time-course of respiratory rate (RR), tidal volume (Vt), and level of pressure support set by the knowledge-based system in cases 22, 23, and 24, who were placed at a high level of pressure support by the knowledge-based system $\left(15 \mathrm{cmH}_{2} \mathrm{O}\right.$ in case $22,17 \mathrm{cmH}_{2} \mathrm{O}$ in case 23 , and $12 \mathrm{cmH}_{2} \mathrm{O}$ in case 24). 
Since these patients were tracheotomized, the KBS would not have recommended extubation for them unless the level of pressure support decreased to $5 \mathrm{cmH}_{2} \mathrm{O}$. This did not occur in any of the three cases. All three patients tolerated the two-hour T-piece trial but were unable to remain without assistance for 48 hours. 


\section{Appendix}

Some general rules used in the knowledge-based system

1. Never reduce the level of pressure support at night, except in case of excessive alveolar ventilation.

2. Try to keep the patient within a zone of "comfort", with a respiratory rate between 12 and 28 breaths per minute, a tidal volume above a minimum threshold, and a $\mathrm{PETCO}_{2}$ below a maximum threshold.

3. Do not let the tidal volume fall below 300 or $250 \mathrm{ml}$ in patients whose body weight is above or below $55 \mathrm{Kg}$, respectively.

4. Keep the respiratory rate between 12 and 28 breaths/min so that the patient is comfortable. In some patients, the upper limit can be moved up to 32 breaths/min.

5. Do not let the end-tidal $\mathrm{CO}_{2}$ exceed $60 \mathrm{mmHg}$ in COPD patients and 50 mmHg in patients with other disorders.

6. Decrease the level of pressure support by $2 \mathrm{cmH}_{2} \mathrm{O}$ when the patient has a stable ventilation within the comfort zone during at least 30 minutes with a level of pressure support less than $20 \mathrm{cmH}_{2} \mathrm{O}$.

7. Decrease the level of pressure support by $4 \mathrm{cmH}_{2} \mathrm{O}$ when the patient has a stable ventilation within the comfort zone during at least 60 minutes with a level of pressure support of $20 \mathrm{cmH}_{2} \mathrm{O}$ or more. 
8. Initiate the preweaning observation period when the level of pressure support is at the minimal value $\left(5\right.$ or $9 \mathrm{cmH}_{2} \mathrm{O}$ in tracheotomized or intubated patients, respectively).

9. Consider that the patient is ready to be weaned after 1 or 2 hours of stable ventilation at the minimal level of pressure support ( 1 hour in those patients with a level of pressure support of $15 \mathrm{cmH}_{2} \mathrm{O}$ or less after one hour of observation, 2 hours in those with an initial level of pressure support greater than $15 \mathrm{cmH}_{2} \mathrm{O}$ ).

10. Adapt the level of pressure support to the physiological needs of the patient and evaluate every two minutes.

11. Consider that a patient requiring a PEEP level above $5 \mathrm{cmH}_{2} \mathrm{O}$ is not ready to be weaned.

12. The maximal level of pressure support is $40 \mathrm{cmH}_{2} \mathrm{O}$.

13. In case of severe hypoventilation, switch to assist-control ventilation with pre-set parameters. 
TABLE 1 : Main characteristics of the 10 patients with negative weaning tests

\begin{tabular}{|c|c|c|c|c|c|c|c|c|c|c|c|}
\hline & Age & Sex & Diagnosis & SAPS & RR & Vt & $\begin{array}{c}\text { RR/ } \\
\text { Vt }\end{array}$ & NIP & $\begin{array}{c}\text { PS } \\
\text { end }\end{array}$ & $\begin{array}{c}\text { Length of } \\
\text { ventilation }\end{array}$ & $\begin{array}{c}\text { Out- } \\
\text { come }\end{array}$ \\
\hline 1 & 59 & $\mathrm{M}$ & Meningo-encephalitis & 15 & 56 & 210 & 267 & 40 & 19 & 12 & $\mathrm{~S}$ \\
\hline 2 & 59 & $\mathrm{M}$ & COPD. Cardiogenic shock & 19 & 34 & 340 & 100 & 50 & 26 & 12 & $\mathrm{D}$ \\
\hline 3 & 61 & $\mathrm{M}$ & Cardiogenic shock & 18 & 35 & 300 & 117 & 30 & 27 & 21 & $\mathrm{D}$ \\
\hline 4 & 54 & $\mathrm{M}$ & COPD. Obesity & 14 & 48 & 300 & 160 & 30 & 17 & 21 & $\mathrm{~S}$ \\
\hline 5 & 44 & $\mathrm{M}$ & $\begin{array}{c}\text { Viral pneumonia. Bone } \\
\text { Marrow transplant }\end{array}$ & 12 & 45 & 150 & 300 & 15 & 30 & 16 & $\mathrm{D}$ \\
\hline 6 & 22 & $\mathrm{~F}$ & Seizures. Inhalation & 8 & 40 & 200 & 200 & 20 & 21 & 7 & $\mathrm{~S}$ \\
\hline 7 & 39 & $\mathrm{M}$ & Peritonitis & 15 & 38 & 200 & 190 & 25 & 15 & 17 & $\mathrm{~S}$ \\
\hline 8 & 58 & $\mathrm{M}$ & $\begin{array}{c}\text { Cardiogenic shock. } \\
\text { Metastatic tumor }\end{array}$ & 12 & 40 & 400 & 100 & 50 & 25 & 14 & $\mathrm{D}$ \\
\hline 9 & 71 & $\mathrm{~F}$ & $\begin{array}{c}\text { Cardiac surgery. } \\
\text { Diaphragm paralysis }\end{array}$ & 9 & 40 & 185 & 216 & 40 & 17 & 8 & $\mathrm{~S}$ \\
\hline 10 & 82 & $\mathrm{M}$ & \begin{tabular}{c} 
COPD. Aspergillosis \\
\hline
\end{tabular} & 11 & 40 & 200 & 200 & 40 & 17 & 14 & $\mathrm{D}$ \\
\hline
\end{tabular}

Abbreviations : SAPS: Simplified Acute Physiology Score (20); RR, Vt, RR/Vt: respiratory rate (breaths.min ${ }^{-1}$ ) tidal volume $(\mathrm{ml})$, and rapid shallow breathing index (breaths. $\mathrm{min}^{-1} . \mathrm{L}^{-1}$ ) after disconnection; NIP: maximal negative inspiratory pressure $\left(\mathrm{cmH}_{2} \mathrm{O}\right)$; PSend: level of pressure support $\left(\mathrm{cmH}_{2} \mathrm{O}\right)$ at the end of the period of knowledge-based system-managed ventilation; length of ventilation: length of ventilation managed by the knowledge-based system (hours); S: Survived; D: Died.

COPD: Chronic Obstructive Pulmonary Disease.

All 10 patients were endotracheally intubated. 
TABLE 2 : Main characteristics of the 28 patients with positive weaning tests

\begin{tabular}{|c|c|c|c|c|c|c|c|c|c|c|c|}
\hline & Age & Sex & Diagnosis & SAPS & RR & $\mathrm{Vt}$ & $\mathrm{RR} / \mathrm{Vt}$ & NIP & $\begin{array}{l}\text { PS } \\
\text { end }\end{array}$ & $\begin{array}{c}\text { Length of } \\
\text { ventilation }\end{array}$ & $\begin{array}{l}\text { Out- } \\
\text { come }\end{array}$ \\
\hline 1 & 62 & $\mathrm{M}$ & COPD. Septic shock & 17 & 24 & 300 & 80 & 40 & 9 & 5 & $\mathrm{~S}$ \\
\hline 2 & 42 & $\mathrm{M}$ & $\begin{array}{c}\text { Cardiogenic. } \\
\text { Pulmonary edema }\end{array}$ & 13 & 16 & 250 & 64 & 40 & 9 & 22 & $\mathrm{~S}$ \\
\hline 3 & 56 & $\mathrm{M}$ & $\begin{array}{l}\text { Cerebral hemorrhage. } \\
\text { Asthma }\end{array}$ & 11 & 21 & 600 & 35 & 35 & 9 & 7 & $\mathrm{D}$ \\
\hline 4 & 40 & $\mathrm{~F}$ & $\begin{array}{l}\text { Guillain-Barré } \\
\text { Pneumonia }\end{array}$ & 14 & 21 & 400 & 52 & 40 & 9 & 15 & $\mathrm{~S}$ \\
\hline 5 & 58 & $\mathrm{~F}$ & Meningo-encephalitis & 14 & 23 & 300 & 77 & 50 & 9 & 4 & $\mathrm{~S}$ \\
\hline 6 & 50 & $\mathrm{~F}$ & Cardiac surgery & 19 & 21 & 350 & 60 & 27 & 9 & 24 & $\mathrm{~S}$ \\
\hline 7 & 62 & $\mathrm{M}$ & Cirrhosis-sepsis & 12 & 26 & 310 & 84 & 33 & 9 & 4 & $\mathrm{~S}$ \\
\hline 8 & 41 & $\mathrm{~F}$ & Drug overdose & 12 & 17 & 250 & 68 & 38 & 9 & 4 & $\mathrm{~S}$ \\
\hline 9 & 56 & $\mathrm{M}$ & Cardiac Surgery & 15 & 22 & 310 & 71 & 25 & 9 & 4 & $\bar{S}$ \\
\hline 10 & 58 & $\mathrm{~F}$ & $\begin{array}{l}\text { Meningitis } \\
\text { (tuberculosis) }\end{array}$ & 15 & 26 & 295 & 88 & 45 & 9 & 23 & $\mathrm{D}$ \\
\hline 11 & 44 & $\bar{M}$ & $\begin{array}{l}\text { Pneumocystis carinii } \\
\text { pneumonia }\end{array}$ & 8 & 26 & 540 & 48 & 45 & 9 & 5 & $\mathrm{~S}$ \\
\hline 12 & 69 & $\mathrm{M}$ & Stroke. Inhalation & 17 & 20 & 560 & 36 & 38 & 9 & 3 & $\bar{D}$ \\
\hline 13 & 79 & $\mathrm{~F}$ & Myasthenia & 10 & 24 & 350 & 69 & 65 & 9 & 6 & $\mathrm{~S}$ \\
\hline 14 & 66 & $\bar{M}$ & $\begin{array}{l}\text { Cardiac surgery. } \\
\text { Mediastinitis } \\
\end{array}$ & 17 & 19 & 450 & 42 & 35 & 9 & 5 & $S$ \\
\hline 15 & 67 & $\mathrm{M}$ & Asthma & 9 & 25 & 570 & 44 & 50 & 9 & 2 & $S$ \\
\hline 16 & 30 & $\mathrm{M}$ & Endocarditis & 9 & 29 & 200 & 145 & 50 & 9 & 9 & $\mathrm{~S}$ \\
\hline 17 & 64 & $\mathrm{~F}$ & $\begin{array}{c}\text { Cardiac surgery. } \\
\text { Diaphragm paralysis }\end{array}$ & 12 & 19 & 370 & 51 & 42 & 9 & 15 & $\mathrm{~S}$ \\
\hline $18^{*}$ & 54 & $\mathrm{~F}$ & Left heart failure & 10 & 30 & 270 & 111 & 60 & 9 & 6 & $\mathrm{D}$ \\
\hline $19^{\circ}$ & 68 & $\bar{F}$ & Cardiogenic shock & 21 & 28 & 350 & 80 & 25 & 25 & 4 & $S$ \\
\hline $20^{\circ}$ & 65 & $\mathrm{M}$ & COPD & 15 & 34 & 240 & 142 & 40 & 26 & 13 & $S$ \\
\hline $21^{*}$ & 62 & $\mathrm{M}$ & COPD. Pneumonia & 17 & 24 & 450 & 53 & 40 & 9 & 24 & $S$ \\
\hline $22^{\circ}$ & 62 & $\mathrm{M}$ & COPD. Pneumonia (T) & 17 & 27 & 300 & 90 & 38 & 15 & 8 & $\mathrm{D}$ \\
\hline $23^{\circ}$ & 84 & $\bar{M}$ & Coma (T) & 15 & 27 & 300 & 90 & 37 & 17 & 17 & $\mathrm{D}$ \\
\hline $24^{\circ}$ & 24 & $\mathrm{M}$ & $\begin{array}{l}\text { Myopathy. Pneumonia } \\
(\mathrm{T})\end{array}$ & 8 & 24 & 180 & 133 & 30 & 11 & 21 & $\mathrm{~S}$ \\
\hline $25^{*}$ & 50 & $\mathrm{~F}$ & Cardiac surgery $(\mathrm{T})$ & 19 & 30 & 295 & 102 & 28 & 17 & 4 & $\mathrm{D}$ \\
\hline $26^{*}$ & 53 & $\mathrm{~F}$ & Obesity. Pneumonia & 10 & 32 & 275 & 116 & 50 & 30 & 4 & $\mathrm{~S}$ \\
\hline $27^{*}$ & 76 & $\mathrm{M}$ & $\begin{array}{l}\text { Tuberculosis sequelae. } \\
\text { Cardiac insufficiency }\end{array}$ & 22 & 40 & 380 & 105 & 60 & 30 & 4 & $\bar{D}$ \\
\hline $28^{*}$ & 65 & $\mathrm{M}$ & $\begin{array}{c}\text { Cardiac surgery. } \\
\text { Diaphragm paralysis }\end{array}$ & 14 & 31 & 280 & 110 & 38 & 19 & 24 & $\mathrm{~S}$ \\
\hline
\end{tabular}

Same abbrevations than in Table 1.

Note that 11 patients (cases 18 to 28 ) could not be separated from the ventilator.

*: patients who failed the T-piece trial.

${ }^{\circ}$ : patients who tolerated the T-piece trial but were unable to remain 48 hours without assistance.

For 19 patients, KBS recommended tracheal extubation (cases 1-18 and 21) 
TABLE 3 : Comparison of positive and negative predictive values

\begin{tabular}{|l|c|c|}
\cline { 2 - 3 } \multicolumn{1}{c|}{} & NPV & PPV \\
\hline T-Piece & $100 \%$ & $77 \%$ \\
RR/Vt & $94 \%$ & $80 \%$ \\
Knowledge-Based System & $100 \%$ & $89 \%$ \\
\hline
\end{tabular}

Abbreviation : RR/Vt indicates rapid shallow breathing index.

For the rapid shallow breathing indexe, we considered that RR/Vt $\leq 100$ predicted a successful weaning outcome. 
Figure 1

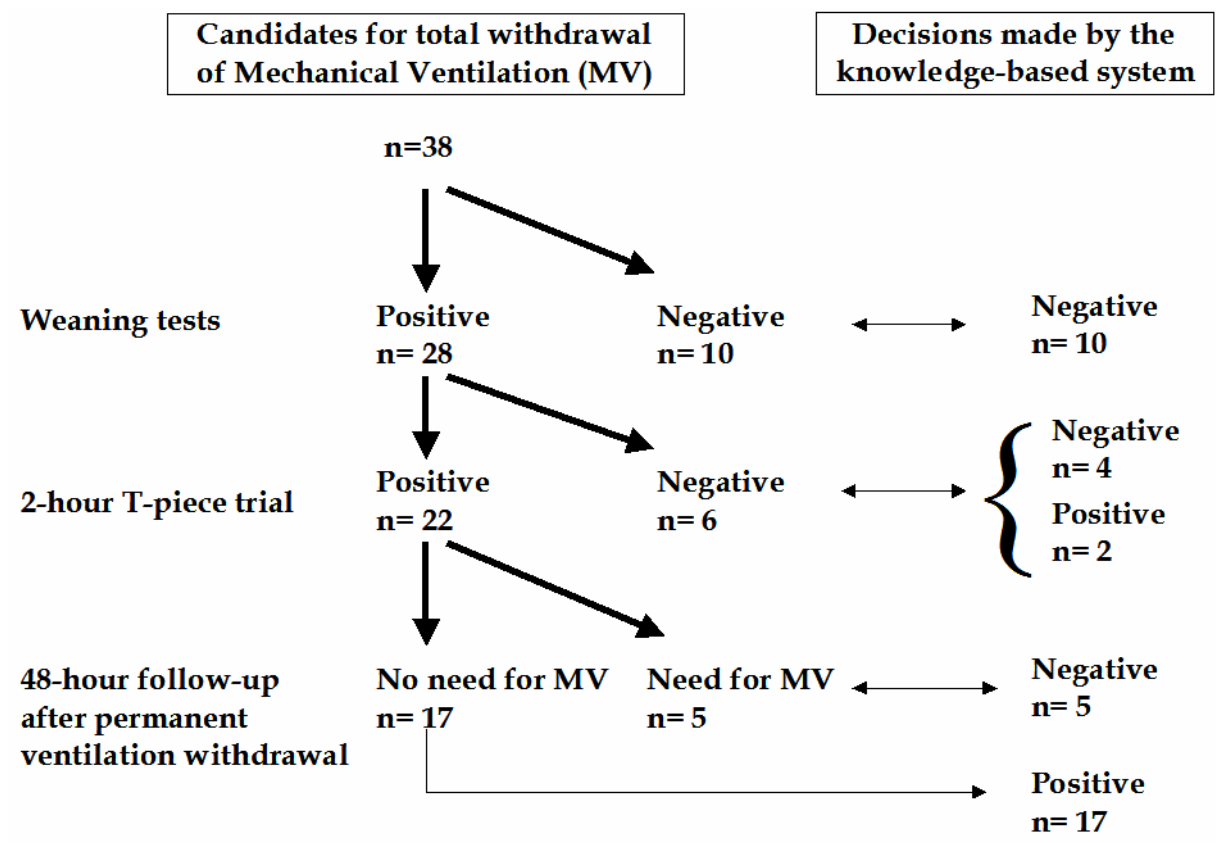


Figure 2
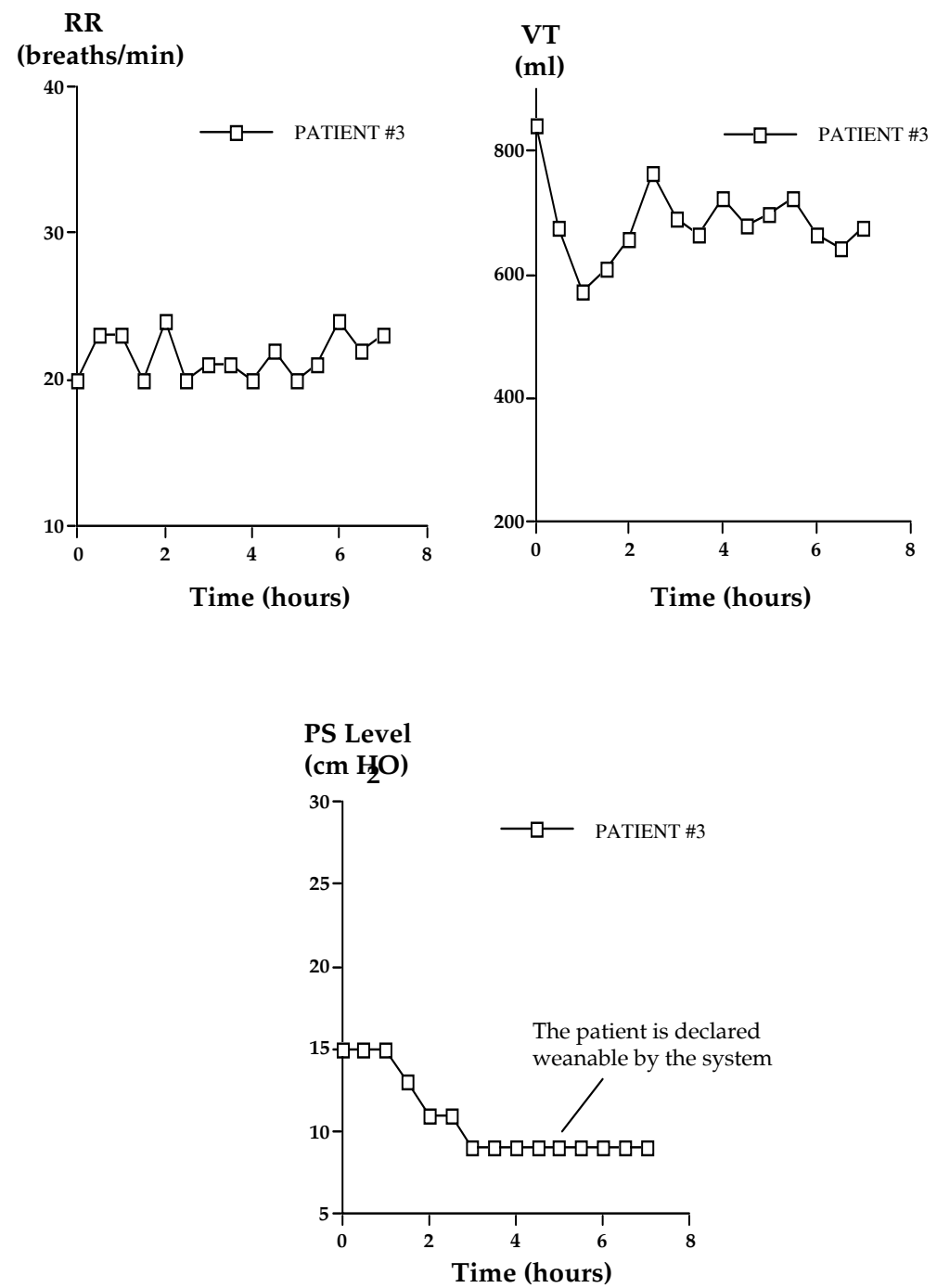
Figure 3
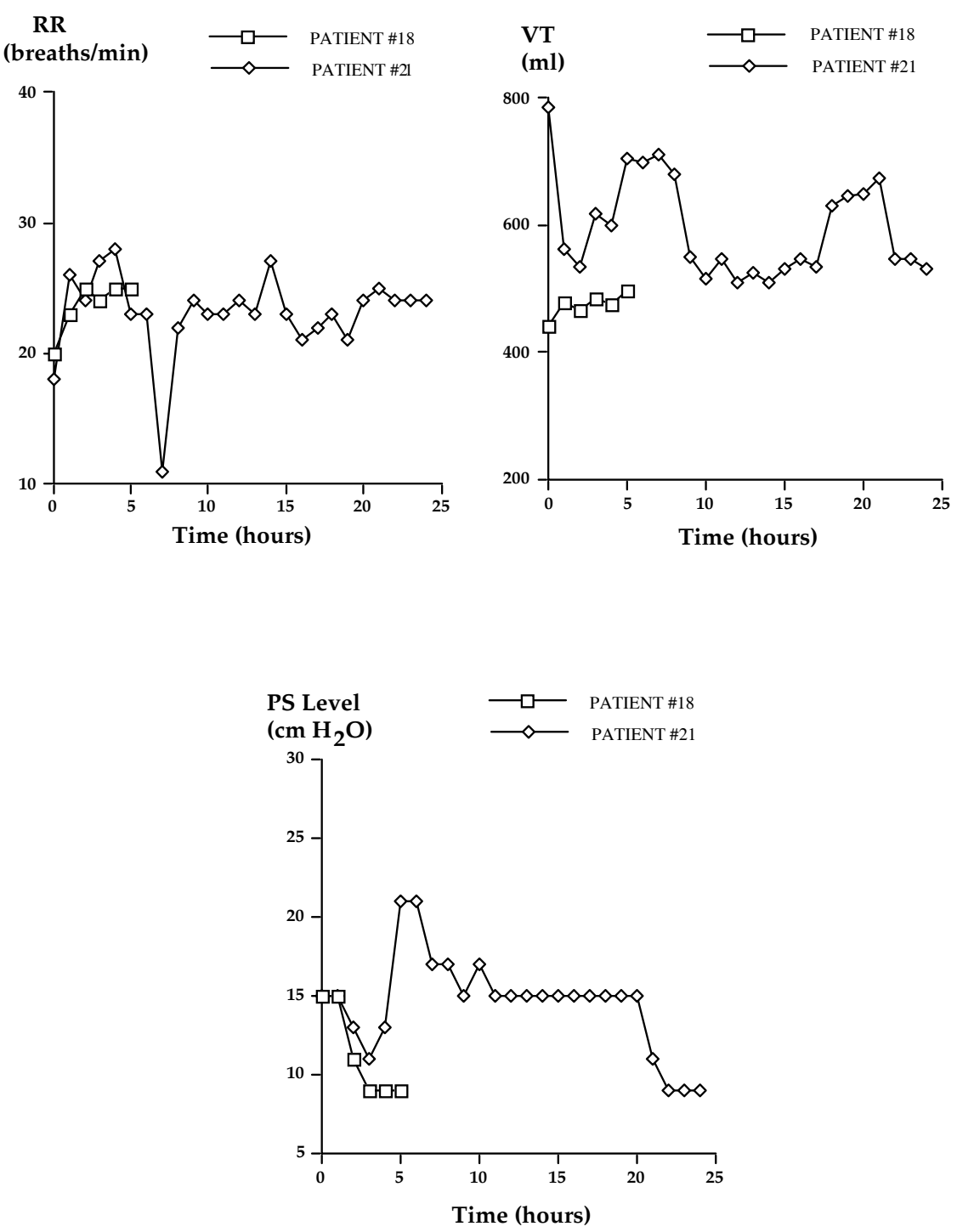
Figure 4
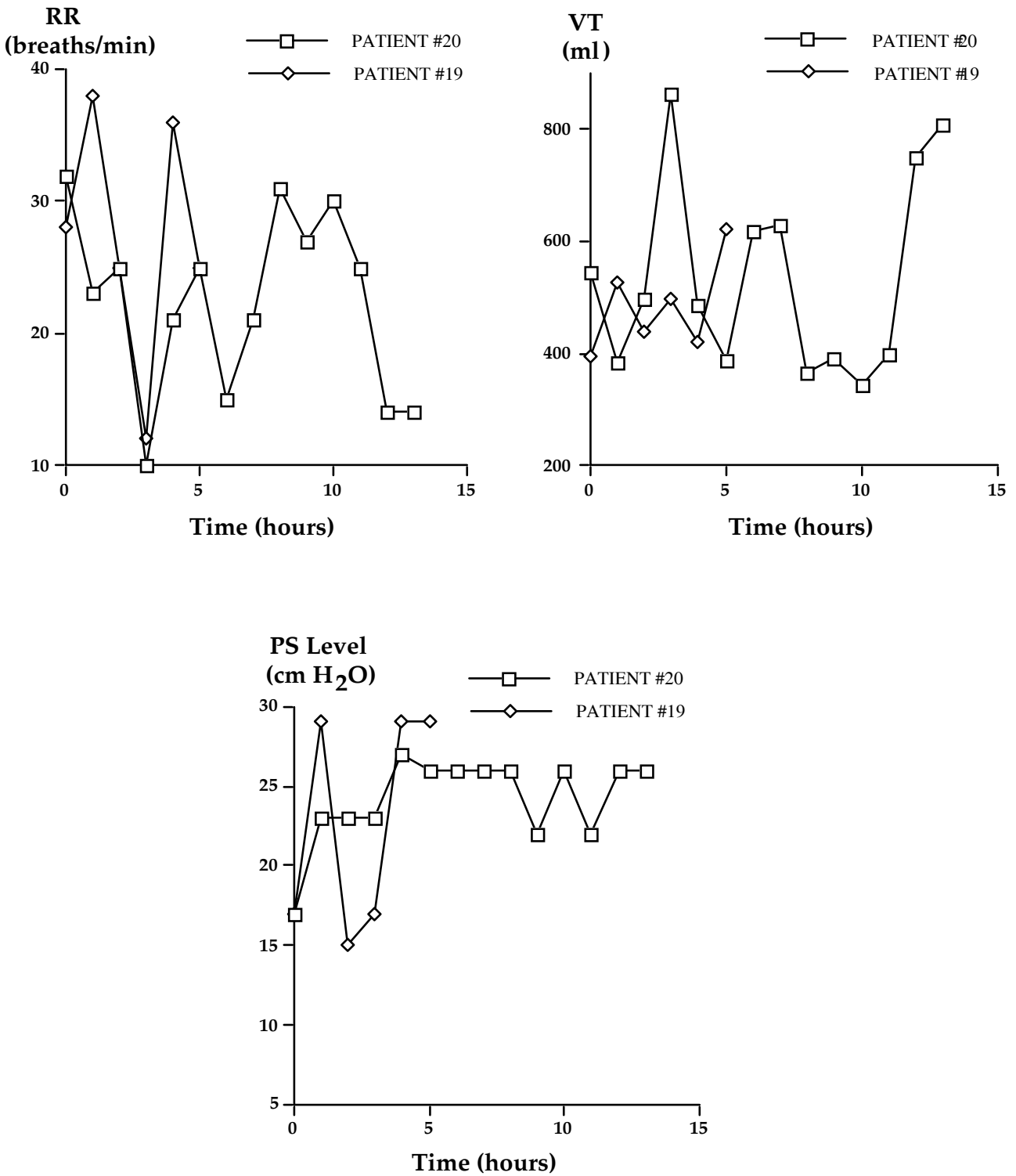
Figure 5
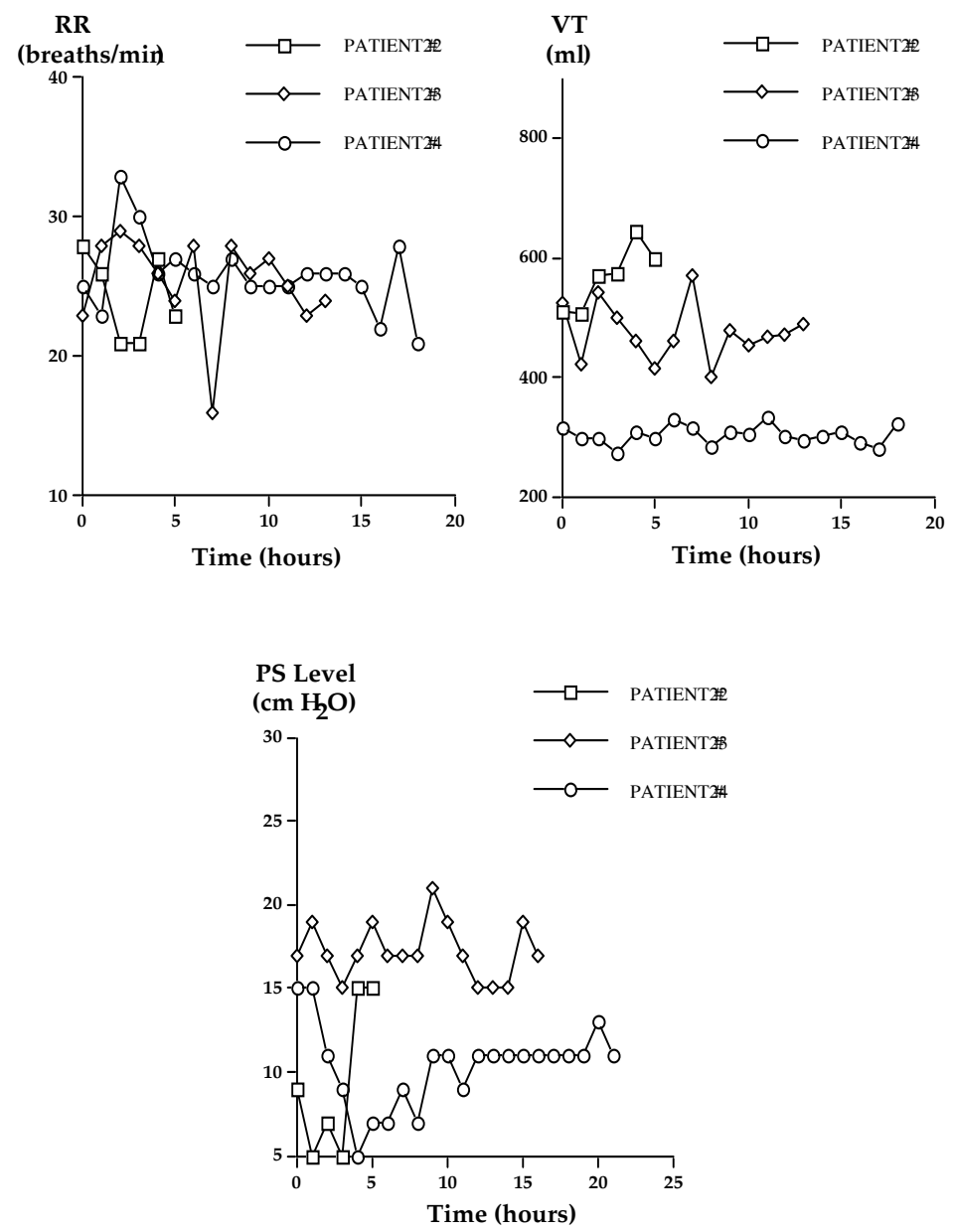